\title{
АНАЛИЗ ОСНОВНЫХ ПОКАЗАТЕЛЕЙ ДОБЫЧИ КАМЕННОГО УГЛЯ НА КОНТИНЕНТАЛЬНЫХ ТЕРРИТОРИЯХ АРКТИЧЕСКОЙ ЗОНЫ РОССИЙСКОЙ ФЕДЕРАЦИИ В ПЕРИОД 2000-2020 Г.Г.
}

\author{
(C) 2021 Кошкарев Максим Владимирович \\ ассистент кафедры государственного и муниципального управления \\ Институт деловой карьеры, Россия, Москва
}

Российская Арктическая зона - это традиционный горнодобывающий регион, производящий широкий спектр полезных ископаемых, среди которых один из наиболее востребованных - уголь. В статье проводится анализ статистических данных добычи каменного угля на территориях Арктической зоны, на основании которого делается вывод о недостаточном росте угольной промышленности в данном регионе. Проанализированы основные проекты, направленные на развитие угледобывающей промышленности и модернизацию транспортной инфраструктуры в Арктике. Предложены направления приоритетной государственной политики для реализации потенциала освоения угольных запасов на территориях Арктической зоны.

Ключевые слова: Арктика, угольные запасы, месторождения, угольная промышленность, транспортная инфраструктура, порты

За последние десятилетия правительства, частные инвесторы и горнодобывающие компании начали рассматривать Арктику как многообещающий источник минерального богатства со значительными месторождениями золота, алмазов, платины, никелевого кимберлита и других драгоценных камней. В некоторой степени этот интерес отражает рост рыночных цен на полезные ископаемые, вызванный, главным образом, значительным ростом спроса со стороны Китая и других стран с развивающейся экономикой за счет ускорения урбанизации и роста населения. Влияние изменения климата также играет свою роль в создании новых возможностей для горнодобывающих секторов [10].

Обширные новые участки земли становятся более доступными в течение более длительных периодов времени в течение года, тем самым продлевая рабочий и разведочный сезон на несколько недель. Северные территории, которые раньше были недоступны или где эксплуатационные расходы были слишком высоки, чтобы оправдать развитие, теперь становятся экономичными. Ожидается, что эта тенденция «открытия» Арктики сохранится и в будущем. Угольная промышленность и другие отрасли, связанные с природными ресурсами, являются ключевыми экономическими факторами для России и создают новые возможности для развития ее северных регионов [6].

Тот факт, что энергетика должна играть важ- ную роль в освоении Арктики, подтверждается также положениями многочисленных стратегических документов, принятых в последнее время. 5 марта 2020 года президент Российской Федерации В.В.Путин подписал Указ об основах государственной политики Российской Федерации в Арктике до 2035 года. 18 марта 2020 года был принят закон о внесении изменений в налоговый кодекс Российской Федерации, вводящий множество фискальных инструментов, направленных на стимулирование добычи энергоресурсов в Арктической зоне. 26 октября 2020 года президент подписал указ об утверждении Стратегии развития Арктической зоны Российской Федерации до 2035 года. Важность региона также подчеркивается в стратегических документах по развитию отечественной энергетики: Энергетическая стратегия Российской Федерации до 2035 г., Стратегия энергетической безопасности и пр.

Рассмотрим динамику добычи каменного угля на Арктических территориях. Поскольку в свободном доступе нет информации в разрезе отдельных месторождений, нам удалось найти укрупненную информацию по угольным бассейнам (рис. 1).

Как мы видим, до 2012 г. наблюдался рост добычи каменного угля в угольных бассейнах Приарктических территорий, в 2013-2014 гг. было падение показателей добычи, с 2017 г. также наблюдается сокращение данных показателей. Помимо этого, целесообразно рассмотреть структу- 
ру перевалки угля по портовым бассейнам (рис. 2).

Анализ данных, представленных на рисунке 2 , демонстрирует, что перевалка угля по арктическому портовому бассейн имеет тенденцию к снижению, несмотря на рост показателей добычи в арктической зоне. Это происходит в том числе потому, что увеличиваются объемы добычи в арктической зоне медленнее, чем на территории других регионов (рис. 3).
Развитие угольной промышленности в Арктике может осложняться ее экстремальным климатом, удаленностью, отсутствием инфраструктуры, а также ограниченным предложением рабочей силы. Большая часть существующей системы железных дорог, морских портов и аэропортов используется недостаточно и не обслуживается. Новые вложения сложно оправдать [5]. В некоторых регионах Арктики все еще остают-

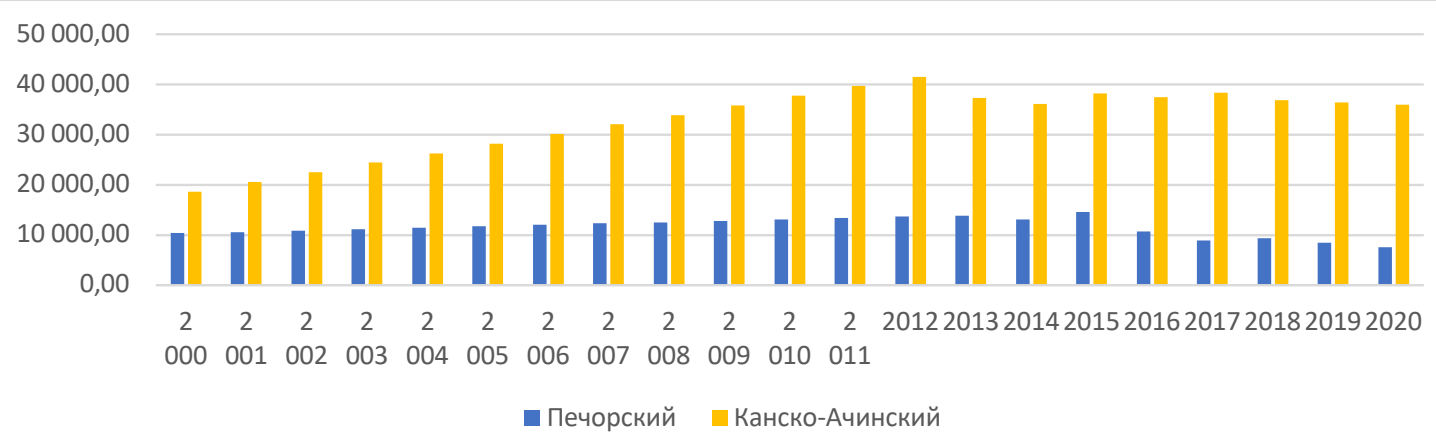

Рис. 1. Добыча угля в России, млн. тонн $[2,11]$

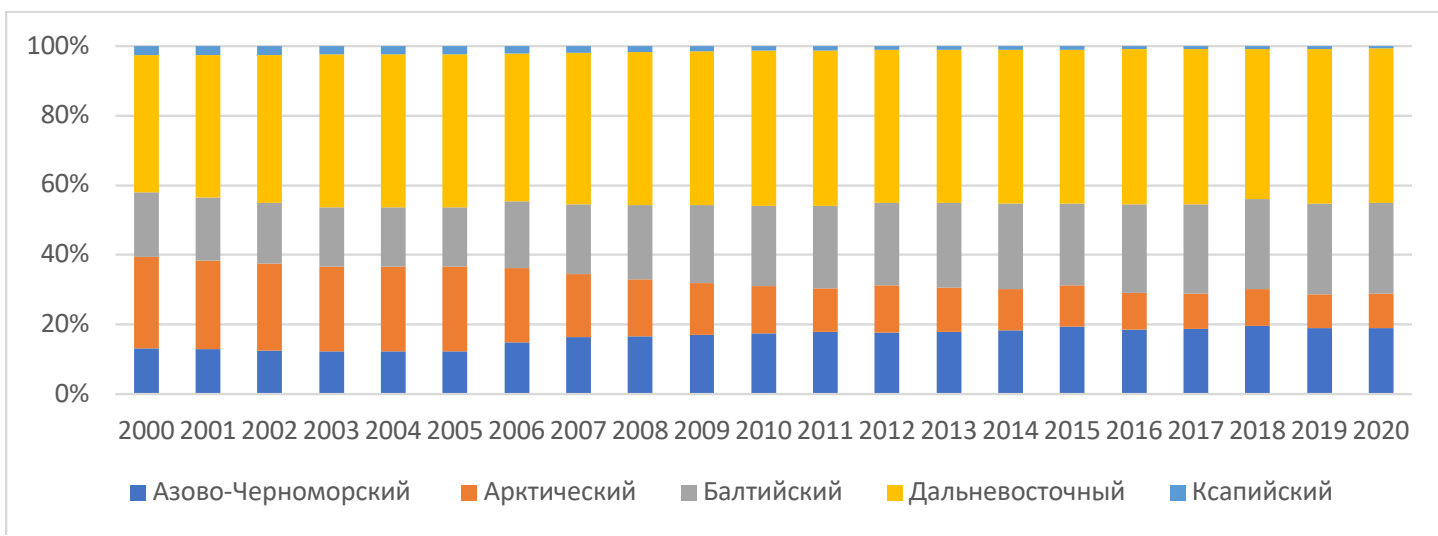

Puc. 2. Структура перевалки угля по портовым бассейнам, \% [2, 11]

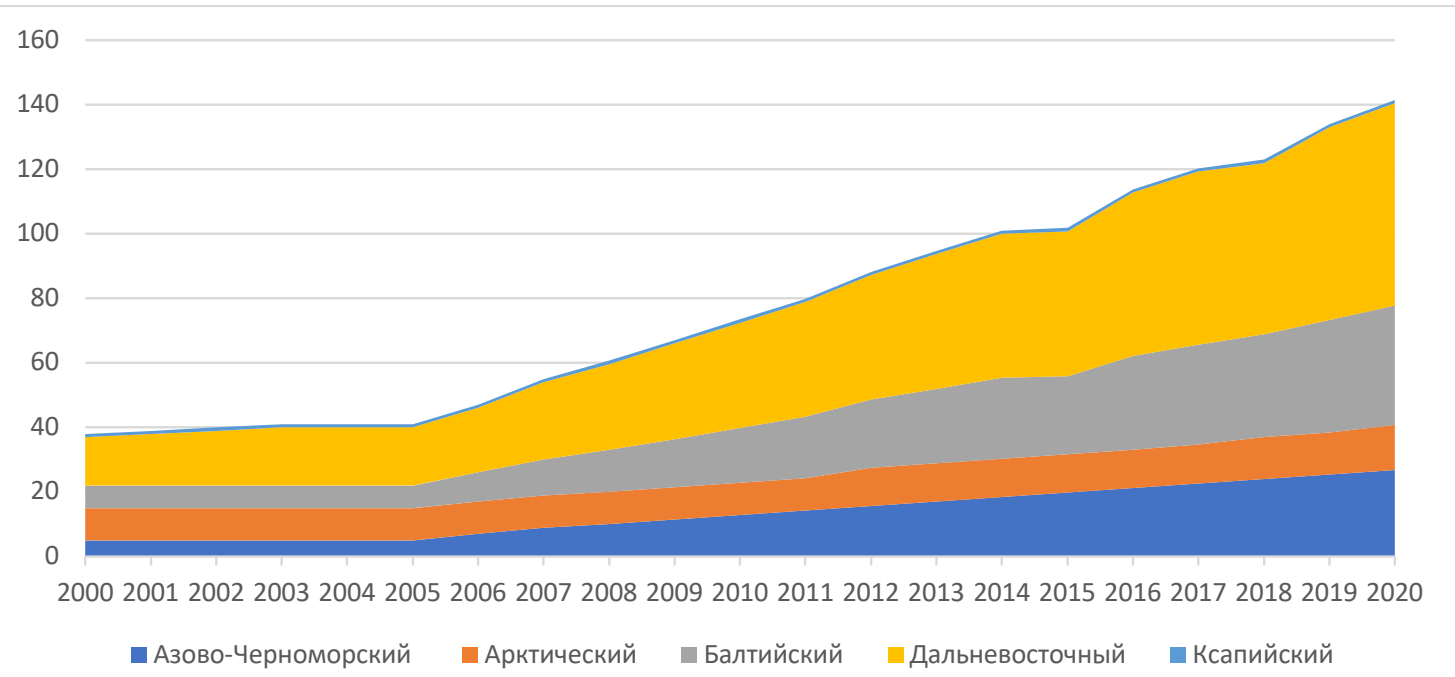

Puc. 3. Динамика объемов перевалки угля по территориям России, млн. тонн [2, 11] 
ся большие ожидания начала добычи угольных ресурсов. По этой причине особенностью России является то, что инвестиции в транспорт будут либо довольно небольшими (при отсутствии обширной разведки ресурсов), либо очень большими (если начнется крупномасштабная разведка и добыча) [1]. Сочетание этих двух факторов особенно затрудняет принятие решений об инвестициях в инфраструктуру [3].

Существует также реальная озабоченность, связанная с социально-экономическими последствиями добычи полезных ископаемых на приарктических территориях, где новые разработки могут негативно повлиять на уже сложившуюся неформальную экономику, состоящую в основном из натуральной охоты, рыболовства и скотоводства, которые являются важным культурным компонентом для качества жизни местных жителей [7].

В результате множества недостатков и негативных воздействий, связанных с добычей полезных ископаемых, все более активно обсуждаются вопросы устойчивости, ответственности и приемлемости добычи полезных ископаемых, а также изменения в способах регулирования и оценки этих вопросов. Добывающая промышленность основана на невозобновляемых ресурсах и, по своей сути, является неустойчивой деятельностью [4]. Принцип «сильной устойчивости» требует, чтобы текущая деятельность человека не исключала возможности для будущего и, следовательно, исключала бы добычу полезных ископаемых как стратегию устойчивого развития. Однако принцип «слабой устойчивости» утверждает, что различные формы капитала, такие как природный, человеческий, социальный, взаимозаменяемы.

В соответствии с этим, добыча полезных ископаемых может способствовать устойчивому развитию, если она дает долгосрочные выгоды (экологические, социальные и экономические), которые равны или превышают ценности, существовавшие до начала разработки. Следовательно, несмотря на то, что добывающие отрасли, связанные с невозобновляемыми ресурсами, такими как горнодобывающая промышленность, по своей сути являются неустойчивой деятельностью, при ответственном подходе они могут привести к улучшению социальных условий, качества жизни и способствовать дальнейшему экономическому развитию. Именно это является императивом развития Арктики и энергети- ческих секторов в Арктической зоне.

Как мы уже видели, в настоящее время в добывающей отрасли России наблюдается рост добычи полезных ископаемых. Однако положительные экономические результаты были достигнуты в основном за счет доразведки существующих рудников и переоценки ресурсов. До 2009 года около 80\% добычи полезных ископаемых приходилось на «старые месторождения», открытые в советское время. В отрасли серьезно не хватает инвестиций на геологоразведку новых месторождений [8].

Движущей силой освоения континентальной Арктики являются амбициозные планы, в частности, новый проект «Восток Ойл», реализуемый компанией «Роснефть» совместно с компанией «Неттигазхолдинг». Его цель - создать крупный энергетический кластер в восточной части приарктических территорий, производить и экспортировать сырую нефть, газ, а также уголь (в конечном итоге до 50 миллионов тонн). В кластер войдут Ванкорская группа (Ванкор, Сузун, Тагул и Лодоче), а на полуострове Таймыр (ВосточноТымырская группа), Западно-Иркинское месторождение (открыто в 2020 г.) и Паячская группа. Помимо данного проекта запланировано еще множество глобальных проектов для развития угольной промышленности (табл. 1).

Осуществление амбициозных инвестиций в уголь в настоящее время находится под вопросом. Проект Востокуголь на полуострове Таймыр все еще находится на предварительной стадии, несмотря на интерес, заявленный крупнейшей угольной компанией Индии Coal India Limited. Согласно первоначальным предположениям, экспорт сырья с планируемого терминала Чайка в порту Диксон должен был начаться в июне 2017 года. Основной причиной замораживания проекта были высокие затраты на добычу и транспортировку угля из полуостров и спад на мировом рынке угля. Свою роль сыграло и судебное разбирательство, возбужденное ФСБ против Арктической горнодобывающей компании, которая должна была выступить основным инвестором.

Несмотря на это, в национальной политике поддержки арктической инфраструктуры произошел значительный сдвиг: от высокоприоритетных стратегических и военных расходов к коммерческим инвестициям в разработку природных ресурсов. В любом случае масштабы, сроки и условия инвестиций часто находятся вне 
Таблица 1. Проекты развития угольной промышленности на Приарктических территориях $[6,8,9,10]$

\begin{tabular}{|l|l|l|l|}
\hline Место реализации & $\begin{array}{c}\text { Объем инвести- } \\
\text { ций, млн.руб. }\end{array}$ & $\begin{array}{c}\text { Срок } \\
\text { реали- } \\
\text { зации }\end{array}$ \\
\hline $\begin{array}{l}\text { Республика Саха } \\
\text { (Якутия) }\end{array}$ & 6136 & Освоение Кабактинского месторождения & 2022 \\
\hline Красноярский край & 284000 & $\begin{array}{l}\text { Разработка антрацитов на полуострове Тай- } \\
\text { мыр (Малолемберовское, Нижнелемберовское } \\
\text { каменноугольные месторождения) }\end{array}$ & 2026 \\
\hline $\begin{array}{l}\text { Республика Саха } \\
\text { (Якутия) }\end{array}$ & 32106 & $\begin{array}{l}\text { Расширенией Денисовской шахты, строитель- } \\
\text { ство Восточной Денисовской шахты }\end{array}$ & 2027 \\
\hline $\begin{array}{l}\text { Республика Саха } \\
\text { (Якутия) }\end{array}$ & 84340 & $\begin{array}{l}\text { Строительство горно-обогатительного ком- } \\
\text { плекса Ингалинский }\end{array}$ & 2027 \\
\hline $\begin{array}{l}\text { Чукотский авто- } \\
\text { номный округ }\end{array}$ & 500 & $\begin{array}{l}\text { Техническое перевооружение Анадырского } \\
\text { месторождения }\end{array}$ & 2035 \\
\hline Республика Коми & 2300 & $\begin{array}{l}\text { Освоение Верхнесыръягинского угольного } \\
\text { месторождения участок «Промежуточный» }\end{array}$ & 2035 \\
\hline $\begin{array}{l}\text { Чукотский авто- } \\
\text { номный округ }\end{array}$ & 6000 & $\begin{array}{l}\text { Увеличение объемов добычи угла на Верхне- } \\
\text { Алькатваамском месторождении угля }\end{array}$ & 2035 \\
\hline $\begin{array}{l}\text { Республика Саха } \\
\text { (Якутия) }\end{array}$ & 398515 & $\begin{array}{l}\text { Строительство Эльгинского угольного ком- } \\
\text { плекса }\end{array}$ & 2030 \\
\hline $\begin{array}{l}\text { Чукотский авто- } \\
\text { номный округ }\end{array}$ & 4167 & Реконструкция морского порта Беринговский & 2022 \\
\hline $\begin{array}{l}\text { Чукотский авто- } \\
\text { номный округ }\end{array}$ & 53100 & $\begin{array}{l}\text { Реконструкция объектом портовой инфра- } \\
\text { структуры грузового района № 1 Мурманского } \\
\text { морского торгового порта }\end{array}$ & 2024 \\
\hline $\begin{array}{l}\text { Мурманская об- } \\
\text { ласть }\end{array}$ & 10675 & Разработка Амаамского месторождения угля & 2035 \\
\hline
\end{tabular}

контроля политических и экономических субъектов арктического региона [1].

Стратегические документы в России подчеркивают важность добывающей деятельности для Арктики и страны и необходимость перехода к новому этапу, основанному на рациональном использовании природных ресурсов, сокращении негативных экологических и социальных воздействий, а также минимизации операционных рисков. Стратегия имеет большое значение для руководства новым процессом принятия решений, однако ей не хватает законодательной поддержки. Большая часть действующего горного законодательства была принята в 1990-х годах в разное экономическое и социальное время и до сих пор требует обновления. Развитие добычи полезных ископаемых в Арктике также обсуждается в региональной политике северных регионов России, в которой этот вопрос рассматривается более подробно.

В России добывающая (угольная) промышленность регулируется Российским Федеральным законом «О недрах», изданным в 1992 г., и Федеральным законом Российской Федерации «О соглашении о разделе продукции» 1995 г. Они устанавливают основу для переговоров по контрактам между государством и инвесторами на добычу полезных ископаемых для распределения доходов от производства. Согласно российскому законодательству, российское государство владеет всеми недрами. Государство может нанять инвестора в качестве подрядчика по добыче полезных ископаемых, но сохраняет за собой право собственности на ресурсы. Российская система лицензирования основана на Законе о недрах, который требует от компаний, 
обладающих правами пользователя на землю, учитывать определенные обязательства, такие как предотвращение промышленных отходов и соблюдение определенных технологических и экологических стандартов качества. В целом, хотя Россия внесла серьезные изменения в свою правовую базу, на практике изменения остались незначительными. В российском контексте отсутствие предсказуемости регулирующей системы, отсутствие координации между властями и нечеткость компетенции на разных уровнях власти создают проблемы.

В России условия проведения экологического мониторинга определены Федеральным законом «Об охране окружающей среды», опубликованным в 2002 г., и Федеральным законом «Об экологической экспертизе» (или Законом об экологической экспертизе 1995 г.). Согласно российскому законодательству горнодобывающие проекты должны проходить экологическую экспертизу для предотвращения возможных воздействий на окружающую среду. Участие общественности считается неотъемлемой частью процесса. В закон были внесены поправки, в соответствии с которыми определение воздействия на окружающую среду больше не включает «связанные социальные, экономические и другие воздействия проекта». Спрос со стороны гражданского общества на участие в процессе принятия решений весьма незначителен. Относительная редкость активности людей и неразвитые механизмы взаимодействия привели к формальному внедрению процессов участия общественности.

По нашему мнению, необходимо выделить пять общих стратегических целей для угольной промышленности:

1) угольная промышленность в гармонии с окружающей средой, культурными ценностя- ми и другой деловой деятельностью;

2) диалог и сотрудничество для продвижения инноваций и роста;

3) рамочные условия и инфраструктура для конкурентоспособности и роста;

4) инновационная угольная промышленность с расширенной базой знаний;

5) всемирно известная, активная и привлекательная угольная промышленность.

Поскольку расширение добычи ресурсов увеличивает риск местных выбросов и потребность в транспортной инфраструктуре, это можно воспринимать как экономическую возможность. В этом направлении должны вестись исследования для разработки и использования инноваций, позволяющих снизить издержки производства, а также уменьшить негативные воздействия на природу. В этом направлении также должны вестись различные мероприятия по привлечению ученых и исследователей.

Подводя итог проведенному исследованию, можно сделать вывод о том, что благодаря богатству природных ресурсов государство имеет большой потенциал для обеспечения эффективного развития промышленных предприятий. Для повышения эффективности угольной промышленности необходимо обновление технического обеспечения, проведение реконструкции и модернизации производства. На это направлены многочисленные стратегические документы и крупные проекты, для эффективной реализации которых необходим мониторинг, аудит и общественный контроль. С другой стороны, достичь поставленных целей можно за счет привлечения иностранных и отечественных инвестиций. Необходимо создать благоприятные условия для поступления инвестиций и разработать эффективную систему государственного регулирования.

\section{Библиографический список}

1. Губанов Д. А. Производство и поставки угля в России / Информационно-аналитический обзор (июнь 2021). М.: ЦДУ ТЭК, 2021. 28 с.

2. Таразанов И.Г., Губанов Д. А. Итоги работы угольной промышленности России за январь-июнь 2021 года // Уголь. 2021. № 9 (1146). С. 25-36.

3. равченко А. В. Оценка запасов угля в Восточной Сибири // Вестник магистратуры. 2019. № 7-2 (94). С. 126128.

4. Панков Д.А., Афанасьев В.Я. Добыча и потребление угля в мире: перспективы для российских экспортеров // Уголь. 2020. № 11 (1136). С. 67-70.

5. Панков Д.А., Афанасьев В. Я., Байкова О. В., Трегубова Е. А. Анализ тенденций мирового рынка угля и направлений российского экспорта // Уголь. 2021. № 3 (1140). С. 23-26. 
6. Клишин В.И., Рогова Т.Б., Шаклеин С. В., Писаренко М.В. Развитие сырьевой базы угольной промышленности России // Известия ТулГУ. Науки о Земле. 2020. № 4. С. 512-521.

7. Плакиткина Л.С., Плакиткин Ю. А. Парижское соглашение по климату, covid-19 и водородная энергетика новые реалии добычи и потребления угля в странах ЕС и Азии в период до 2040 года // Горная промышленность. 2021. № 1. С. 83-90.

8. АО «Воркутауголь»: путь к стабильности // Уголь. 2019. № 3 (1116). С. 29-31.

9. Варфоломеева Т. В. Тугнуйский угольный разрез: слагаемые успеха работы предприятия // Уголь. 2021 . № 8 (1145). С. 26-28.

10. Петрунин А.М., Семенов А.С., Молодых С. С. Анализ перспектив разработки угольных месторождений в арктической зоне Чукотской автономной области // Московский экономический журнал. 2020. № 8. С. 74-85.

11. ЦДУ ТЭК, АО «Росинформуголь». URL: https://www.cdu.ru/ 